\title{
Characterization of the Phytophthora infestans Population in the Columbia Basin of Oregon and Washington from 1992 to 1995
}

\author{
Jeffrey S. Miller, Philip B. Hamm, and Dennis A. Johnson
}

First and third authors: Department of Plant Pathology, Washington State University, Pullman 99164-6430; second author: Department of Botany and Plant Pathology, Hermiston Agricultural Research and Extension Center, Oregon State University, Hermiston 97838. Accepted for publication 28 March 1997.

\section{ABSTRACT}

Miller, J. S., Hamm, P. B., and Johnson, D. A. 1997. Characterization of the Phytophthora infestans population in the Columbia Basin of Oregon and Washington from 1992 to 1995. Phytopathology 87:656-660.

Isolates of Phytophthora infestans collected from 1992 to 1995 from potato fields in the Columbia Basin of Oregon and Washington were analyzed for compatibility type, metalaxyl sensitivity, and glucose-6phosphate isomerase (Gpi) genotype. In 1992, 30 of 31 isolates were of the US-1 multilocus genotype. A single metalaxyl-resistant isolate of the US-6 (A1 Gpi 86/100) genotype was found near the end of the growing season. In 1993, only 2 of the 59 isolates collected were A1 isolates with Gpi 86/100. Ten isolates were of the A2 compatibility type, seven with
Gpi 100/111, two with Gpi 100/100, and one was undetermined. The remaining isolates were metalaxyl-resistant A1 compatibility types with either Gpi $100 / 100$ or $100 / 111$. The first A2 isolates in the Columbia Basin were found in 1993. In 1994, 10 of 18 isolates were of the US-1 genotype. The remaining isolates were US-6 and US-8 genotypes. In $1995,97 \%$ of 268 isolates tested were of the US- 8 genotype. Five isolates were A2 compatibility type with Gpi 100/122. One A2, metalaxylresistant isolate was Gpi 100/100/111, and two A1 isolates were Gpi 100/111/122. The population of $P$. infestans quickly changed between 1992 and 1995, from a population comprised almost exclusively of the US-1 genotype to a population represented by new or recombinant genotypes.
Late blight, caused by Phytophthora infestans (Mont.) de Bary, is one of the most destructive diseases of cultivated potato (Solanum tuberosum ssp. tuberosum L.). Evidence that the central highlands of Mexico is the center of origin for the pathogen has been provided by the widespread diversity in virulence characteristics and neutral allozyme markers in the Mexican population $(9,14,24)$. Outside Mexico, a single clonal lineage existed worldwide until the 1980s $(9,12,29)$. This lineage was characterized by the A1 compatibility type and sensitivity to the phenylamide fungicide metalaxyl. Isolates resistant to metalaxyl $(3,4)$ and belonging to the A2 compatibility type $(18,21)$ were detected in Europe during the 1980s. Since that time, numerous studies have reported the spread of the A2 compatibility type and metalaxyl resistance in potato-growing regions around the world. These newer strains have increased in frequency and replaced the old clonal strain in the Netherlands $(8,29)$, Germany (29), Poland $(29,30)$, and various regions of the United States $(12,15)$. The spread of the A2 compatibility type to areas where the A1 compatibility type has existed creates the possibility of sexual recombination. Oospores produced by sexual recombination may provide another source of initial inoculum for initiating epidemics and lead to offspring with characteristics different from the parental types (9).

Allozyme analysis has become an effective tool for identifying variation in $P$. infestans populations $(8,11,12,15,27-31)$. A study of isolates from the United States and Canada in 1992 identified 11 multilocus genotypes (15). The four most common multilocus genotypes, US-1, US-6, US-7, and US-8, were detected from more than three locations and were widespread in the United States. Before 1992, only two multilocus genotypes had been detected previously in the United States and Canada (US-1 and US-6).

Corresponding author: J. S. Miller; E-mail address: jsmiller@mail.wsu.edu

Publication no. P-1997-0418-04R

(C) 1997 The American Phytopathological Society
Multilocus genotypes were based on compatibility type, allozyme genotype, and DNA fingerprints. These multilocus genotypes could be differentiated from each other on the basis of glucose-6phosphate isomerase (Gpi) allozyme analysis alone. Allozyme analysis of peptidase (Pep) alleles gave only two allozyme genotypes, 92/100 and 100/100. The numbers represent the distance migrated by alleles relative to the most common allele during electrophoresis (1). In the case of Pep 92/100, the 92 allele migrates $92 \%$ as far as the 100 allele. Currently, 14 multilocus genotypes have been identified in the United States $(11,15 ; \mathrm{S}$. B. Goodwin and W. E. Fry, personal communication). Four of the most recently identified multilocus genotypes (US-11 through US-14) can be identified by compatibility type and Gpi allozyme genotype.

Allozyme analysis was performed in the studies mentioned above by starch gel electrophoresis, which is a labor-intensive and time-consuming procedure (13). A more economical technique that uses cellulose acetate electrophoresis was developed in 1995 for use as a quick diagnostic tool to aid in control of late blight by providing information related to metalaxyl sensitivity and compatibility type identity (13). The relationship between allozyme genotype, metalaxyl sensitivity, and compatibility type was thought to be effective as long as populations of $P$. infestans remained clonal.

In the Columbia Basin of north-central Oregon and south-central Washington, late blight first was documented in 1947 (2). This region, comprising $\sim 65,000$ ha of cultivated potatoes in 1995 , is surrounded by mountains on all sides, separating it from the potato-producing regions of western Washington and other areas of Oregon and from Montana, British Columbia, and southern Idaho. Late blight has caused severe damage in recent years, affecting $\sim 25,000$ ha in 1992, 31,000 ha in 1993, 770 ha in 1994, and 65,000 ha in $1995(19,20)$. From 1947 to 1990 , the population of $P$. infestans in this area was composed of the old clonal US-1 lineage $(9,11)$. The situation changed when isolates resistant to metalaxyl appeared in 1991 (5) and when the A2 compatibility type was detected in 1993 (17). Almost all P. infestans isolates collected in 1992 were sensitive to metalaxyl (17). The frequency 
of metalaxyl resistance and the A2 compatibility type were unknown, however.

This study was undertaken to determine the composition of the P. infestans population from 1992 to 1995 by characterizing isolates obtained from potato fields in the Columbia Basin for metalaxyl sensitivity, compatibility type, and Gpi genotype. A knowledge of the population structure of $P$. infestans in the Columbia Basin may supply information on metalaxyl resistance, sources of initial inoculum for epidemics, and potential for oospore production, which in turn will aid in developing better late blight control strategies.

\section{MATERIALS AND METHODS}

Isolate collection and maintenance. Isolates of $P$. infestans were obtained from naturally infected potato foliage throughout the Columbia Basin of Oregon and Washington from 1992 to 1995 (Table 1). This region extends for $\sim 180 \mathrm{~km}$, from Umatilla and Morrow counties in north-central Oregon to Grant and Adams counties in south-central Washington. Potato fields were monitored by field workers several times each week during the growing season. When late blight was first observed in any field, P. B. Hamm or D. A. Johnson usually was notified. Most infected fields were sampled during the low-incidence years of 1992 and 1994 from the time late blight was first reported in the region until midAugust to give a nearly complete sample of fields through midgrowing season. During the severe epidemic years of 1993 and 1995, when all fields in some counties were infected, representative isolations were done randomly in generalized locations throughout the Columbia Basin. In 1992 and 1993, only one isolate was obtained from each field, because populations within fields were believed to be clonal (10). In 1994 and 1995, multiple samples were taken from each field. Fewer samples were collected in the northern portion of the Basin, in Grant and Adams counties, because late blight was either not present or occurred at a lower incidence and later in the season than in the southern portion of the Basin. In all, 388 isolates were collected from 178 potato fields from 1992 to 1995.

Cultures were obtained by transferring sporangia from the margin of a single sporulating lesion to rye extract agar (26) amended with $100 \mu \mathrm{g}$ each of penicillin, pimaricin, and polymyxin per $\mathrm{ml}$ or by removing small areas of infected leaf tissue near the lesion margin and plating the tissue on rye extract agar containing $10 \mu \mathrm{l}$ of pimaricin, 250 units of ampicillin, and $10 \mu \mathrm{g}$ of rifampicin per $\mathrm{ml}$. Isolates were derived by transferring a hyphal tip or single sporangium to unamended rye extract agar. Isolates were maintained on rye extract agar at $18^{\circ} \mathrm{C}$ in darkness and were transferred every 4 to 5 weeks.

Isolate characterization. Each isolate was tested for compatibility type and metalaxyl sensitivity. Allozyme genotype was determined for all isolates collected in 1992, 1994, and 1995 and 36 of 59 isolates collected in 1993. Compatibility types were determined by pairing each isolate against two known A1 and two known A2 isolates on rye extract agar. Agar plates were kept in darkness at $18^{\circ} \mathrm{C}$ for 14 days and then examined for oospores with a dissecting microscope. Isolates Pi 94 (US-6) and Fi 2 (US-1) were used as A1 testers, and isolates 584 (US-8) and 302 (US-7) were used as A2 testers. The compatibility type and multilocus genotype of the tester isolates was confirmed by B. A. Fry (Cornell University, Ithaca, NY).

Metalaxyl sensitivity of isolates was evaluated by placing isolates singly on plates containing rye extract agar amended with $0.1,1.0,10.0$, and $100.0 \mu \mathrm{g}$ of technical-grade metalaxyl per ml. Classification of strains as sensitive or resistant was determined following a modification of the scheme used by Deahl et al. (6), using $10.0 \mu \mathrm{g}$ of metalaxyl per $\mathrm{ml}$ as the critical value. Sensitive and resistant isolates displayed $<10 \%$ and $>10 \%$ growth, respectively, compared to the control. Isolates Fi 2 (US-1) and 382 (US-1) and 584 (US-8) and 537 (US-11) were used as standards for sensitive and resistant responses, respectively. These standards were chosen because of their vigorous growth on rye extract agar in the absence of metalaxyl.

Isolates were analyzed for Gpi allozyme genotype (13). Assay samples were obtained by scraping mycelium from 2- to 3-weekold cultures with a spatula and placing the mycelium in a $1.5-\mathrm{ml}$ centrifuge tube containing $1 \mathrm{ml}$ of deionized distilled water. Tubes were stored on ice between steps for the remainder of the procedure. After centrifugation at $13,000 \times g$ for $5 \mathrm{~min}$, approximately half the supernatant in each tube was poured off and discarded. The pellet in each tube was ground with a plastic pestle attached to a high-speed electric hand-held drill until the sample mixture was homogenized. The tubes were centrifuged again at $13,000 \times g$ for $5 \mathrm{~min}$. Aliquots of supernatant were electrophoresed and stained with agar overlays for Gpi (13). The following standards (identified by B. A. Fry) were used: Fi 2 (US-1), Pi 94 (US-6), 301 and 302 (US-7), 584 (US-8), and 537 (US-11). Only two or three standards were run per plate, depending on the phenotype of the isolates being compared, i.e., 584, 301, and 302 with A2 isolates; 537 and Pi 94 with A1 metalaxyl-resistant isolates; and Fi 2 with A1 metalaxyl-sensitive isolates. When a combination of phenotypes was analyzed together, a combination of appropriate standards was used.

\section{RESULTS}

All isolates collected in 1992 were of the A1 compatibility type. Of 31 isolates, 30 were metalaxyl sensitive with Gpi 86/100 and belonged to the US-1 multilocus genotype. One isolate collected near the end of the growing season, on 18 August, was metalaxyl resistant with Gpi 100/100 and was a US-6 genotype (Table 2).

Preliminary analysis of samples by DNA fingerprinting indicated that isolates with the same Gpi allozyme genotypes collected in 1993 had significant genetic variation. This diversity within isolate groupings based on identical Gpi allozyme genotypes was not found in other years (R. W. Sandrock and W. E. Fry, personal communication). Because of this, no US designations were made for 1993 isolates.

In 1993, 59 isolates were collected from the Columbia Basin. Of these, 46 were A1, and 13 were A2 compatibility types (Table 2). All A2 isolates were resistant to metalaxyl. Of the A1 Columbia Basin isolates, 6 were sensitive, and the remaining 40 were resistant to metalaxyl. Allozyme analysis was done on 2 of the 6 A1 metalaxyl-sensitive isolates, 26 of the 40 A1 metalaxyl-resistant isolates, and 9 of the $10 \mathrm{~A} 2$ metalaxyl-resistant isolates. The isolates not analyzed for allozyme genotype did not survive in culture until the time when allozyme analysis was performed. The two A1 metalaxyl-sensitive isolates had Gpi 86/100 (Table 2). Of the A1

TABLE 1. Origin and number of Phytophthora infestans isolates collected from potato fields in the Columbia Basin of Oregon and Washington from 1992 to 1995

\begin{tabular}{lrrrr}
\hline & \multicolumn{4}{c}{ Number of isolates } \\
\cline { 2 - 5 } County of Origin & 1992 & 1993 & 1994 & 1995 \\
\hline Oregon & 2 & 30 & 8 & 113 \\
$\quad$ Umatilla & 24 & 17 & 0 & 58 \\
$\quad$ Morrow & & & & \\
Washington & 4 & 6 & 0 & 43 \\
$\quad$ Benton & 1 & 2 & 7 & 15 \\
Franklin & 0 & 4 & 1 & 11 \\
$\quad$ Walla Walla & 0 & 0 & 2 & 0 \\
$\quad$ Grant & 0 & 0 & 0 & 5 \\
Adams & & & & \\
Total & 31 & 59 & 18 & 245 \\
Number of fields & 21 & 55 & 8 & 71 \\
\hline
\end{tabular}

a Late blight incidence was very low from 1992 to 1994. 
metalaxyl-resistant isolates, 16 had Gpi 100/111, 4 had Gpi 100/100/111, and 6 had Gpi 100/100. The Gpi 100/111 allozyme genotype was found in 7 of the $10 \mathrm{~A} 2$ isolates, and the Gpi $100 / 100$ allozyme genotype was found in 2 of the $10 \mathrm{~A} 2$ isolates.

In 1994, 10 of 18 isolates were metalaxyl sensitive and were of the US-1 genotype (A1 Gpi 86/100; Table 2). Of the remaining eight metalaxyl-resistant isolates, five were A2, and three were A1. All of the A2 compatibility type isolates were of the US-8 genotype (Gpi 100/111/122). All of the A1 metalaxyl-resistant isolates were of the US-6 genotype (Gpi 100/100).

In 1995, all isolates were metalaxyl resistant, and $97 \%$ of these isolates belonged to the US-8 genotype (Table 2). Five isolates with the A2 compatibility type had Gpi 100/122, and one A2 isolate had Gpi 100/100/111. Of 268 isolates, 2 were characterized as A1 with Gpi 100/111/122.

\section{DISCUSSION}

The population structure of $P$. infestans in the Columbia Basin of Oregon and Washington changed between 1992 and 1995. In 1991, metalaxyl resistance was detected in a limited area late in the season in the northern Columbia Basin of Washington (5). In our study, one metalaxyl-resistant isolate was found in 1992. This isolate was collected during late August, near the end of the growing season. The frequency of metalaxyl-sensitive isolates decreased from $97 \%$ in 1992 to $10 \%$ in 1993 and increased to 37\% in 1994. Metalaxyl-sensitive isolates were not detected in 1995.

The reduced frequency of metalaxyl-sensitive isolates during this period probably was not due to selection by metalaxyl. Metalaxyl was not recommended to growers for late blight control after 1992. Metalaxyl was still applied, however, one to two times on potatoes planned for long-term storage, to control storage rots, making selection due to metalaxyl similar from 1993 to 1995. These applications for control of storage rots were made at the late flowering stage of the crop and again 2 weeks later. Fields already were infested by this time in 1995 , particularly fields planted with susceptible cultivars where metalaxyl was usually not applied because tubers were not going to be placed in storage. In addition, very large numbers of volunteer potato plants that were not treated with metalaxyl were present during this period in the region due to mild weather conditions. A sample of 30 fields each year gave a mean of $9,023,2,670$, and 850 volunteers per ha for 1992, 1993, and 1994, respectively. These volunteers would have provided additional opportunities for spore production and dispersal of metalaxyl-sensitive strains. If metalaxyl-sensitive strains were present in 1995 , they probably would have been found, es- pecially considering the number of $P$. infestans samples collected and the widespread area from which they were collected.

Metalaxyl-resistant isolates were most likely introduced via infected potato seed brought into the Columbia Basin at the beginning of each growing season. Metalaxyl-resistant isolates have been reported from at least one seed-production area where seed is purchased for use in the Columbia Basin (6). In addition, a previous study dealing with metalaxyl resistance suggested that metalaxyl-resistant isolates migrated into the United States, rather than arising by mutation and then selection (16).

In our study, $10.0 \mu \mathrm{g}$ of metalaxyl per $\mathrm{ml}$ was used as the critical value for determining metalaxyl resistance (6). Metalaxyl sensitivity, according to our criteria, corresponded to the level of sensitivity previously identified with compatibility type and $G p i$ genotype. Metalaxyl resistance is one of the defining characteristics of the US-8 genotype $(15,16)$. All isolates with the A2 compatibility type and Gpi 100/111/122 in this study were resistant to metalaxyl. Deahl et al.'s (6) original classification defined isolates with 10 to $60 \%$ growth on metalaxyl-amended media $(10.0 \mu \mathrm{g} / \mathrm{ml})$ was metalaxyl intermediate. This classification seems too broad for practical use. In our study, the mean growth for isolates collected in 1995 when tested on $10.0 \mu \mathrm{g}$ of metalaxyl per $\mathrm{ml}$ was $57 \%$ (variance $=0.028014$ ) compared to the unamended control. Separating isolates at $60 \%$ growth compared to the control is arbitrary and does not help in classifying isolates. Only two isolates classified as metalaxyl resistant had growth less than $20 \%$ compared to the control. All US-1 isolates found in 1992 and 1994 had growth less than $10 \%$ of the control when tested on metalaxyl-amended agar, making the division between metalaxyl resistance and sensitivity at $10 \%$ logical. These findings are similar to those of Goodwin et al. (16) who analyzed metalaxyl resistance in US-8 isolates. The criteria used by Goodwin et al. (16) identified isolates as sensitive if growth on agar with $5 \mu \mathrm{g}$ of metalaxyl per $\mathrm{ml}$ was less than $40 \%$ of growth on the control. They tested 49 US- 8 isolates at a concentration of $5 \mu \mathrm{g}$ of metalaxyl per $\mathrm{ml}$ and found the mean growth to be $62.3 \%$ of the growth of the control. The similarity between Goodwin et al.'s (16) test and our results indicates that metalaxyl resistance among isolates of the US-8 genotype is similar over wide geographic areas.

The A2 compatibility type was found for the first time in the Columbia Basin in 1993 (17). These new A2 isolates were Gpi 100/111 and Gpi 100/100. Additionally, A1 isolates with Gpi 100/100/111 and Gpi 100/111 also were detected for the first time in 1993. The isolates with these traits had not been found previously in the Columbia Basin and represent a genetically diverse group of isolates, as determined by DNA fingerprinting (R. W.

TABLE 2. Characteristics of Phytophthora infestans and number and percentage (in parentheses) of isolates of each genotype collected in the Columbia Basin of Oregon and Washington during each year from 1992 to 1995



${ }^{\mathrm{a}}$ Isolates were tested on rye extract agar amended with $10 \mu \mathrm{g}$ of technical-grade metalaxyl per ml. Sensitive $=<10 \%$ growth compared to the control; resistant $=$ $>10 \%$ growth compared to the control.

${ }^{\mathrm{b}}$ Glucose-6-phosphate isomerase.

${ }^{c}$ Due to diversity in DNA fingerprinting within groups of isolates with the same Gpi genotype, genotype designations were not assigned for these isolates. Not all isolates survived in culture until the time when Gpi genotype was analyzed.

d Isolates from the US-1 genotype.

e Isolates from the US-6 genotype.

${ }^{\mathrm{f}}$ Isolates from the US-8 genotype.

$\mathrm{g}$ Isolates not currently assigned to a genotype. 
Sandrock and W. E. Fry, personal communication). The A2 Gpi 100/100 combination has been found in British Columbia (15). These novel A1 and A2 strains probably were transported into the Columbia Basin in infected seed, because the A2 compatibility type and the Gpi 111 allele had not been found in previous years. The novel strains either did not survive in the field during the winter of 1993 to 1994, were not reintroduced with infected seed, or did not become established in 1994, because none was detected after 1993. If any novel strains did escape detection in 1994, they probably did not survive until the 1995 growing season. The large sample size in 1995 greatly increased the chance of detecting any of these novel strains. In contrast, some isolates may have survived the winter, because A1 Gpi 86/100 and A1 Gpi 100/100 strains were found during all years between 1992 and 1994. These isolates could have overwintered in tubers, either in storage or in the field, or could have been established from infected seed.

During the spring of 1994, isolates were found with the A2 compatibility type and Gpi 100/111/122 for the first time. This strain also was most likely carried on infected seed from another location, because Gpi 122 had not been found previously in the Columbia Basin. Isolates of the A2 compatibility type and Gpi $100 / 111 / 122$ dominated in 1995. These isolates had low DNA fingerprinting variation (15), indicating they were probably clonal, which is representative of the US-8 genotype. Isolates not of this genotype in 1995 were either A2 with Gpi 100/100/111 or Gpi $100 / 122$ or A1 with Gpi 100/111/122. None of these combinations of traits had been found previously in the Columbia Basin. The A2 Gpi 100/122 could have arisen by the loss of the Gpi 111 allele from the US-8 genotype. The A2 Gpi 100/100/111 and the A1 Gpi $100 / 111 / 122$ have not been given US designations at this point in time.

Sexual recombination could account for some of the new combinations of compatibility type and Gpi allozyme genotype found in 1993 and 1995. In a study analyzing isolates from Poland, a unique combination of Gpi alleles (90/90) was interpreted to be one line of evidence for sexual recombination (30). In the Columbia Basin, a cross between A1 Gpi 100/100 strains (present in 1992 and 1993) and A2 Gpi 100/111 strains (typical of the US-7 genotype, found previously in the United States) could have produced potential offspring with A2 Gpi 100/100 and A1 Gpi 100/111 strains. The potential offspring were found between 16 August and 9 September, near the end of the growing season. Both possible parents (A1 Gpi 100/100 and A2 Gpi 100/111) were found during mid-July in two counties in Oregon. Oospores of $P$. infestans can germinate and infect plant tissue as soon as 7 days after they are formed (7). Diseased tissue samples were not examined for oospores, however, so no physical evidence exists that supports sexual reproduction.

The sudden occurrence in 1994 and dominance in 1995 of US-8 genotype isolates may indicate this genotype is more fit than other strains. Isolates of the US-8 genotype infect young shoots from infected seed faster than other genotypes (22). This ability could provide the US-8 genotype with a competitive advantage in infecting new plant material during the spring. Additionally, the US- 8 genotype is more aggressive in terms of tissue colonization, latent period, and spore production than other genotypes present in the Columbia Basin (23).

Analyzing the Gpi allozymes provided a fast method for characterizing isolates (13) but could not be used reliably in 1993 to designate genotypes due to the variation in DNA fingerprinting data, which was due to either sexual recombination or introduction of a diverse population on seed. Genotypes of isolates collected in all other years correlated well with the expected compatibility type and metalaxyl sensitivity for each isolate. In 1995, combinations of compatibility type and Gpi alleles not reported previously were found. Identification of genotype by Gpi allozyme assay alone, thus, was not sufficient to categorize isolates in the Columbia Basin. Additionally, compatibility and metalaxyl- sensitivity tests should be continued. With both compatibility types present in the region, the potential exists for sexual recombination to occur. If recombination has occurred, the population of $P$. infestans is no longer clonal, and the use of Gpi genotypes for isolate identification may become obsolete. In addition, sexual recombination will lead to oospore formation in the field, potentially increasing the longevity of the pathogen in the field (7). As of yet, oospores have not been found in the Columbia Basin. If oospores do form, they may become a significant factor in the survival of $P$. infestans during winters and in the production of inoculum during the spring $(7,25)$. Management of late blight then would be expected to be more difficult due to overwintering oospores and an aggressive population of $P$. infestans.

\section{ACKNOWLEDGMENTS}

Plant Pathology New Series 0249, Project 0678, Department of Plant Pathology, College of Agriculture and Home Economics Research Center, Pullman, WA. We thank B. A. Fry, S. B. Goodwin, and W. E. Fry for help with allozyme analysis; G. Pelter, T. Cummings, K. Pritchard, L. Douhan, J. Jaeger, and B. Geary for technical assistance; and L. M. Carris, D. A. Inglis, W. E. Fry, and S. B. Goodwin for comments on the manuscript.

\section{LITERATURE CITED}

1. Allendorf, F. W., Mitchell, N., Ryman, N., and Stahl, G. 1977. Isozyme loci in brown trout (Salmo trutta L.): Detection and interpretation from population data. Hereditas 86:179-190.

2. Anonymous. 1947. Discover blight menace to late potato crops. Prosser Record-Bulletin, Prosser, WA. September 25, 1947.

3. Cooke, L. R. 1981. Resistance to metalaxyl in Phytophthora infestans in northern Ireland. Proc. Br. Crop Prot. Conf. Pests Dis. 2:641-650.

4. Davidse, L. C., Looijen, D., Turkensteen, L. J., and Van der Wal, D. 1981. Occurrence of metalaxyl-resistant strains of Phytophthora infestans in Dutch potato fields. Neth. J. Plant Pathol. 87:65-68.

5. Deahl, K. L., DeMuth, S. P., Pelter, G., and Ormrod, D. J. 1993. First report of resistance of Phytophthora infestans to metalaxyl in eastern Washington and southwestern British Columbia. Plant Dis. 77:429.

6. Deahl, K. L., Inglis, D. A., and DeMuth, S. P. 1993. Testing for resistance to metalaxyl in Phytophthora infestans isolates from northwestern Washington. Am. Potato J. 70:779-795.

7. Drenth, A., Janssen, E. M., and Govers, F. 1995. Formation and survival of oospores of Phytophthora infestans under natural conditions. Plant Pathol. 44:86-94.

8. Fry, W. E., Drenth, A., Spielman, L. J., Mantel, B. C., Davidse, L. C., and Goodwin, S. B. 1991. Population genetic structure of Phytophthora infestans in the Netherlands. Phytopathology 81:1330-1336.

9. Fry, W. E., Goodwin, S. B., Dyer, A. T., Matuszak, J. M., Drenth, A., Tooley, P. W., Sujkowski, L. S., Koh, Y. J., Cohen, B. A., Spielman, L. J., Deahl, K. L., Inglis, D. A., and Sandlan, K. P. 1993. Historical and recent migrations of Phytophthora infestans: Chronology, pathways, and implications. Plant Dis. 77:653-661.

10. Fry, W. E., Goodwin, S. B., Matuszak, J. M., Spielman, L. J., Milgroom, M. G., and Drenth, A. 1992. Population genetics and intercontinental migrations of Phytophthora infestans. Annu. Rev. Phytopathol. 30:107-129.

11. Goodwin, S. B., Cohen, B. A., Deahl, K. L., and Fry, W. E. 1994. Migration from northern Mexico as the probable cause of recent genetic changes in populations of Phytophthora infestans in the United States and Canada. Phytopathology 84:553-558.

12. Goodwin, S. B., Cohen, B. A., and Fry, W. E. 1994. Panglobal distribution of a single clonal lineage of the Irish potato famine fungus. Proc. Natl. Acad. Sci. 91:11591-11595.

13. Goodwin, S. B., Schneider, R. E., and Fry, W. E. 1995. Use of celluloseacetate electrophoresis for rapid identification of allozyme genotypes of Phytophthora infestans. Plant Dis. 79:1181-1185.

14. Goodwin, S. B., Spielman, L. J., Matuszak, J. M., Bergeron, S. N., and Fry, W. E. 1992. Clonal diversity and genetic differentiation of Phytophthora infestans populations in northern and central Mexico. Phytopathology 82:955-961.

15. Goodwin, S. B., Sujkowski, L. S., Dyer, A. T., Fry, B. A., and Fry, W. E. 1995. Direct detection of gene flow and probable sexual reproduction of Phytophthora infestans in northern North America. Phytopathology 85: 473-479.

16. Goodwin, S. B., Sujkowski, L. S., and Fry, W. E. 1996. Widespread distribution and probable origin of resistance to metalaxyl in clonal genotypes of Phytophthora infestans in the United States and Canada. Phyto- 
pathology 86:793-800.

17. Hamm, P. B., Fry, B. A., and Jaeger, J. 1994. Occurrence and frequency of metalaxyl insensitivity and mating types of Phytophthora infestans in the Columbia Basin of Oregon and Washington. (Abstr.) Phytopathology 84:1123.

18. Hohl, H. R., and Iselin, K. 1984. Strains of Phytophthora infestans with A2 mating type behaviour. Trans. Br. Mycol. Soc. 83:529-530.

19. Johnson, D. A., Alldredge, J. R., and Vakoch, D. L. 1996. Potato late blight forecasting models for the semiarid environment of south-central Washington. Phytopathology 86:480-484.

20. Johnson, D. A., Cummings, T. F., Hamm, P. B., Rowe, R. C., Miller, J. S., Thornton, R. E., Pelter, G. Q., and Sorensen, E. J. 1997. Potato late blight in the Columbia Basin: An economic analysis of the 1995 epidemic. Plant Dis. 81:103-106.

21. Ko, W. H. 1994. An alternative possible origin of the A2 mating type of Phytophthora infestans outside Mexico. Phytopathology 84:1224-1227.

22. Marshall, K. D., and Stevenson, W. R. 1996. Transmission of Phytophthora infestans from infected seed potato tubers to developing sprouts. (Abstr.) Am. Potato J. 73:370-371.

23. Miller, J. S., Johnson, D. A., and Hamm, P. B. 1995. Aggressiveness of Phytophthora infestans isolates in the Pacific Northwest. (Abstr.) Phytopathology 85:1127.

24. Niederhauser, J. S. 1991. Phytophthora infestans: The Mexican connection. Pages 24-45 in: Phytophthora. J. A. Lucas, R. C. Shattock, D. S.
Shaw, and L. R. Cooke, eds. Cambridge University Press, England.

25. Pittis, J. E., and Shattock, R. C. 1994. Viability, germination and infection potential of oospores of Phytophthora infestans. Plant Pathol. 43: 387-396.

26. Ribeiro, O. K. 1978. A Source Book of the Genus Phytophthora. J. Cramer, Vaduz, Germany.

27. Shattock, R. C., Shaw, D. S., Fyfe, A. M., Dunn, J. R., Loney, K. H., and Shattock, J. A. 1990. Phenotypes of Phytophthora infestans collected in England and Wales from 1985 to 1988: Mating type, response to metalaxyl and isoenzyme analysis. Plant Pathol. 39:242-248.

28. Spielman, L. J. 1991. Isozymes and population genetics of Phytophthora. Pages 231-241 in: Phytophthora. J. A. Lucas, R. C. Shattock, D. S. Shaw, and L. R. Cooke, eds. Cambridge University Press, England.

29. Spielman, L. J., Drenth, A., Davidse, L. C., Sujkowski, L. J., Gu, W., Tooley, P. W., and Fry, W. E. 1991. A second world-wide migration and population displacement of Phytophthora infestans? Plant Pathol. 40: 422-430.

30. Sujkowski, L. S., Goodwin, S. B., Dyer, A. T., and Fry, W. E. 1994. Increased genotypic diversity via migration and possible occurrence of sexual reproduction of Phytophthora infestans in Poland. Phytopathology 84:201-207.

31. Tooley, P. W., Fry, W. E., and Villarreal-Gonzales, M. J. 1985. Isozyme characterization of sexual and asexual Phytophthora infestans populations. J. Hered. 76:431-435. 